\title{
Aging and risk taking: toward an integration of cognitive, emotional, and neurobiological perspectives
}

This article was published in the following Dove Press journal:

Neuroscience and Neuroeconomics

25 April 2014

Number of times this article has been viewed

\author{
Robin Shao ${ }^{1,2}$ \\ Tatia MC Lee ${ }^{1-3}$ \\ 'Laboratory of Neuropsychology, \\ ${ }^{2}$ Laboratory of Social Cognitive \\ Affective Neuroscience, ${ }^{3}$ The \\ State Key Laboratory of Brain and \\ Cognitive Sciences, The University \\ of Hong Kong, Hong Kong
}

\begin{abstract}
In this article, we characterize the relationship between natural aging and risky decision making through an integration of cognitive, emotional, and neurobiological theories on the effects of natural aging. Based on the existing evidence, we propose that the positivity emotional bias in elderly adults steers them away from taking high risks and toward more conservative approaches during decision making as part of their positive emotional regulatory strategies. However, aging is also associated with marked declines in cognitive functioning, such as attention and working memory, as well as impaired reinforcement-based associative learning, which arises from anatomical and functional declines in the dopaminergic transmission systems and in distinct brain regions such as the dorsolateral prefrontal cortex and hippocampus. In consequence, elderly adults may deviate from their usual conservative stance and toward more risk-taking tendencies, as observed in a subset of studies, if the demands of the risk-taking task exceed their cognitive and learning capacities. More empirical investigations are needed to determine the key factors that influence elderly individuals' decision making and behavior in risky situations. Research in this field is likely to have important practical implications for the financial and medical decision making of elderly adults, as well as promoting designated help targeting the elderly population in making important life decisions.
\end{abstract}

Keywords: risky decision making, aging, insula, cognition, dopaminergic system

\section{Introduction}

The elderly make up an increasingly significant proportion of the global population due to rising life expectancy and falling birth rates, signifying the impact of their financial and health decisions on society. ${ }^{1}$ Aging is associated with a wide range of neurobiological and cognitive declines (for reviews, see Grady ${ }^{2}$ and Bäckman et $\mathrm{al}^{3}$ ) affecting their decision-making ability. However, elderly adults frequently face everyday important issues related to health care, illness, and financial matters. Advances in understanding how the decision-making processes in elderly adults differ from those in young adults, and how these differences are related to the effects of aging on general cognitive capacities ${ }^{4}$ and on neurobiological systems, ${ }^{5}$ are essential both for promoting the welfare of the elderly population and for improving the infrastructure and economy of society as a whole. ${ }^{6}$

"Decision making" is defined as the selection of action among alternatives with the aim of producing optimal outcomes. ${ }^{7}$ One important component of decision making is "risk taking", defined as the propensity to select an option potentially leading to either relatively large gain or loss, instead of an alternative associated with relatively small gain or loss. ${ }^{8}$ The present review focuses on the discussion of the effects of aging on risky
Correspondence: Tatia MC Lee

Rm 656, The Jockey Club Tower,

Department of Psychology, The

University of Hong Kong, Pokfulam Road,

Hong Kong

Tel +85239178394

Fax +852 28190978

Email tmclee@hku.hk 
decision making in association with aging-related emotional alterations and cognitive and neurobiological declines, with the aim of producing an integrative account of the relationship between natural aging and risk taking. A sample of existing laboratory and real-life measures of risk taking is included in Table 1. As will become apparent later, this diversity in measures might be one of the main reasons for the inconsistent findings on the effect of aging on risk taking in the existing literature. Note that, in this review, the terms "aging" and "elderly" refer to late adulthood beyond age 60 .

This review begins with a general discussion of various decision-making theories and the modulatory influence of affect on decision making under risk. This is followed by a summary of the past literature on the neurobiological basis of risky decision making, covering the functional roles of both the dopaminergic neurotransmission systems and distinct cortical and subcortical brain regions. The existing empirical findings on the relationships between natural aging and risk seeking/risk aversion in decision making are then addressed, noting both consistencies and inconsistencies in the findings, and this is followed by a discussion of the possible causes of the disparities in findings. Finally, the effects of aging on risky decision making are linked to the emotional, cognitive, and neurobiological aspects of natural aging in an attempt to provide an integrative account of aging and risk taking.

\section{Risky decision-making theories and the modulatory effect of mood Economic decision-making theories}

Researchers have proposed various theoretical models to characterize human economic decision-making processes (see Mellers ${ }^{9}$ for a review). These models could be extended to explain decision making in other domains. For example, according to the "subjective expected utility theory", ${ }^{10}$ an individual selects the options that have maximal "subjective expected utilities" - the positive values of the potential outcomes to the individual. The individual weights these utilities by the subjective probability of their occurrences, or how likely the individual believes they would be to occur following the selection of a particular option. This theory explains risk aversion by proposing that the utility function is concave, such that utility increases rapidly at first, but gradually slows down as a function of gain. Thus, when choosing between a sure gain of US $\$ 100$ and a $10 \%$ chance of gaining US $\$ 1,000$, the risk-averse person would choose the sure gain, although the two options have mathematically equal expected values (US \$100). (Conceptually, risk aversion is different from loss aversion, although they are closely associated with each other ${ }^{14}$ and may share common basis of personality constructs such as neuroticism. $)^{73}$

Unlike the subjective expected utility theory, the "prospect theory"11 proposes that during decision making, individuals tend to overestimate very small probabilities but underestimate large probabilities. Also, individuals assess the utilities of gains and losses according to some reference point, such as status quo. Originating from this reference point, the increase (or decrease) of utility as a function of gain (or loss) slows down as the gain (or loss) grows larger, but the pain (or subjective loss) resulting from a loss is generally greater than the pleasure (or subjective gain) resulting from a gain. This asymmetry in the utility function in the gain and loss domains could explain loss aversion.

Table I A sample of existing measures of risk taking

\begin{tabular}{|c|c|c|}
\hline Risk-taking measure & Measure type & Description \\
\hline lowa Gambling Task ${ }^{57}$ & Behavioral task & $\begin{array}{l}\text { Measures the tendency to act on immediate prospects while } \\
\text { ignoring long-term consequences }\end{array}$ \\
\hline Cambridge Gambling Task ${ }^{54}$ & Behavioral task & $\begin{array}{l}\text { Measures the tendency to place low-win probability, high-gain bets } \\
\text { rather than high-win probability, low-gain bets }\end{array}$ \\
\hline Bet preference test ${ }^{180}$ & Behavioral task & $\begin{array}{l}\text { Assesses risk preference while choosing between bets that may vary } \\
\text { on win/loss probability, win/loss magnitude, expected value, and risk }\end{array}$ \\
\hline Risky-gains task ${ }^{73}$ & Behavioral task & $\begin{array}{l}\text { Assesses propensity for risk-taking behaviors risking large losses } \\
\text { for large gains }\end{array}$ \\
\hline $\begin{array}{l}\text { Behavioral Investment Allocation Strategy } \\
\text { task, or BIAS } 55,133\end{array}$ & Behavioral task & $\begin{array}{l}\text { Assesses propensity for irrationally choosing high-risk financial } \\
\text { options over the safe option }\end{array}$ \\
\hline Life-experience inventory ${ }^{181}$ & Self-report questionnaire & Assesses past risk-taking behaviors in life \\
\hline Choice Dilemmas Questionnaire ${ }^{102}$ & Self-report questionnaire & $\begin{array}{l}\text { Assesses risk preference while responding to hypothetical life } \\
\text { scenarios }\end{array}$ \\
\hline $\begin{array}{l}\text { Measures in specific domains } \\
\text { (eg, financial, medical) })^{88,1 / 2}\end{array}$ & $\begin{array}{l}\text { Self-report questionnaire, } \\
\text { real-life decision making }\end{array}$ & Assesses domain-specific risk-taking tendency \\
\hline
\end{tabular}

Note: Detailed descriptions of the tasks are included in the main text throughout the chapters. 
There are also theories that incorporate an explicit element of risk, such as the "risk-return models of economic decision making". According to this theory, the individual determines the expected reward of each alternative and its associated risk or variance of reward. Then the individual calculates the value of the alternative as the risk-corrected expected reward. ${ }^{12}$

At this point, it is worth noting that when choosing between alternatives of equal expected values during oneshot financial decisions, risk seeking and risk aversion, as described, are generally not considered violations of normative decision making and could be well explained by financial theories such as the subjective expected utility theory and the prospect theory. ${ }^{10,11}$ In contrast, persistent preference for riskier response options that lead to long-term financial loss over safer options that lead to long-term financial gain, even following multi-trial learning, can be considered nonnormative, or pathological, and reflect neuropsychological deficits, as will be discussed later in this review.

\section{The influence of mood/affect on risky decision making}

Two prominent theories offer predictions on the influence of mood or affect on people's risk-taking tendencies during decision making. One is called the "affect infusion model" (AIM) and proposes that positive (eg, happiness) and negative (eg, sadness) affects bias people's recall and processing of stimuli in positive and negative directions, respectively. ${ }^{13}$ Thus, the AIM predicts risk seeking in a positive mood and risk aversion in a negative mood, because a happy person would process stimuli more favorably and be more optimistic about the consequence of risk taking, whereas the opposite would be true for someone in negative mood. The other theory is called the mood maintenance hypothesis (MMH). ${ }^{14}$ It posits that people in good moods are motivated to maintain their positive states, which results in them being less willing to engage in risky activities associated with potential heavy losses that would obliterate their positive mood. In contrast, people in negative mood states are more willing to take risks for the potential large gains that would significantly improve their mood. Thus, the AIM and MMH make exactly opposite predictions on the influence of mood on risky decision making. Notably, the MMH places a heavy emphasis on emotional regulation, higher levels of which have been observed among elderly individuals. ${ }^{15,16}$ Thus, the MMH can be a useful model for explaining the effect of aging on risky decision making.

Previous studies have generated findings that are consistent with the MMH, such that induced positive affect is associated with increased loss or risk aversion, especially when the probability or magnitude of potential losses was high. ${ }^{17-20}$ For example, participants with induced positive affect were less likely to invest large amounts of money in gambling, ${ }^{18}$ and demanded a higher probability of winning for accepting a gamble when the stakes were high.${ }^{17}$ Conversely, individuals with induced sadness exhibited risk-seeking tendencies on a probabilistic gambling task, ${ }^{20}$ when selecting between jobs, ${ }^{20}$ and in response to hypothetical life scenarios. ${ }^{21}$ Although there exists other research evidence supporting predictions by the AIM, or risk seeking associated with positive mood and risk aversion associated with negative mood, ${ }^{22}$ previous research has overall provided substantial evidence suggesting that the employment of mood-regulatory strategies aiming at maintaining positive mood states is generally associated with lesser tendency to engage in high-risk activities, at least under some conditions. ${ }^{14}$

\section{The neurobiological basis of risky decision making Risk taking and the dopamine system}

Risky decision making entails integration of the magnitudes and probabilities of rewards and punishments in determining the expected value and risk associated with any given response options. ${ }^{9}$ Unsurprisingly, the dopaminergic neural systems are critically involved in risky decision-making processes. ${ }^{5}$ Extensive empirical evidence suggests that the dopaminergic systems provide fundamental neural basis for the prediction, signaling, and learning of the value and risks associated with rewards ${ }^{23-26}$ and punishments..$^{24,27}$ Electrophysiological studies have also revealed tonic midbrain dopaminergic activity that correlated positively with the level of uncertainty or risk of rewards. ${ }^{28}$

One pharmacological intervention study explicitly examined the relationship between the level of dopaminergic functions and risk taking on a probabilistic gambling task. ${ }^{29}$ Participants could bet on either the number 5 or 25 , leading to either the gain (if winning) or loss (if losing) of the same number of points. Thus, betting on 5 and 25 qualify as low- and high-risk behaviors, respectively. The results suggested that a single dose of the dopamine receptor agonist pramipexole increased participants' risk-taking behaviors. At the neural level, pramipexole, relative to placebo, led to reduced activations in rostral basal ganglia, including the ventral striatum, in response to monetary gains. These results support a direct influence of striatal dopaminergic functions on risky decision making.

Further, it was shown that, compared with both the $\mathrm{val} / \mathrm{met}$ and val/val genotype carriers, individuals carrying 
the met/met genotype of the Catechol-O-Methyltransferase (COMT) gene, which codes the COMT protein that is responsible for the degradation and inactivation of dopamine, showed greater reward responsiveness and more risk-taking behaviors, ${ }^{30}$ as measured by the Balloon Analogue Risk Task (BART). ${ }^{31}$ Another study found that the seven-repeat allele of the dopamine D4 receptor gene DRD4 predicted 25\% more risk taking in financial decision making. ${ }^{32}$ These findings are important evidence in support of the involvement of dopaminergic systems in risky decision making.

Note that although we present only a discussion of the dopaminergic circuitries here, other neurotransmitters such as serotonin are likely to influence risky decision making. For example, Tanaka et $\mathrm{al}^{33}$ found that the serotonin system controls people's processing of immediate and delayed rewards through modulating neural activities in the ventral and dorsal parts of the striatum, respectively, with low serotonin levels promoting processing of immediate rewards and high serotonin levels promoting processing of delayed rewards. Reward delay-discounting is an important aspect of impulsivity and can be associated with risk-seeking behaviors (Bechara et $\left.\mathrm{al}^{34}\right)$.

\section{Risk taking and distinct neural circuitries}

Midbrain dopaminergic neurons project heavily to striatal regions such as the ventral striatum and caudate nucleus, which have been shown to code the value, ${ }^{35,36}$ probability, ${ }^{37-39}$ and magnitude ${ }^{35,40,41}$ of rewards. Additionally, the ventral striatum is involved in predicting and signaling aversive stimuli, ${ }^{42}$ whereas the caudate nucleus may be primarily involved in reinforcement-directed action selection. ${ }^{43}$ Similar functional roles have been assigned to other dopaminergic areas, such as the ventromedial prefrontal cortex (VMPFC), ${ }^{44,45}$ the ventrolateral prefrontal cortex (VLPFC)/orbitofrontal cortex (OFC), ${ }^{25,46}$ the dorsolateral prefrontal cortex (DLPFC), ${ }^{47,48}$ and the insular cortex. ${ }^{35,36}$

Both the ventral and dorsal striatum (caudate) are involved in learning about reward contingencies and forming reinforcement-based actions. ${ }^{49,50}$ Electrophysiological studies indicate that neurons in both ventral and dorsal striatum are specifically responsive to reward-related information during instrumental behaviors. ${ }^{51,52}$ In addition, the ventral striatum showed sustained activations correlated with reward uncertainty during anticipation. ${ }^{48}$ Studies have also found ventral striatal activations in response to winning relative to losing outcomes on a probabilistic gambling task, ${ }^{53}$ and to high levels of conflict in risky decision making. ${ }^{54}$ Similarly, other research found caudate activities in response to relative gain outcomes on a financial risky decision-making task. ${ }^{55}$ Further, the striatum can influence motor output either through projections to the substantia nigra or through efferents to the ventral pallidum. ${ }^{56}$ Thus, there is compelling evidence suggesting that the ventral and dorsal striatum are specifically implicated in learning and utilizing reward contingency information in guiding behaviors.

Previous research revealed maladaptive behaviors among patients with VMPFC lesions in risky situations, such as on the Iowa Gambling Task (IGT), designed to measure individuals' behaviors toward response options associated with larger immediate gain but even larger long-term loss and high risk (disadvantageous), and options associated with smaller immediate gain but long-term overall gain and low risk (advantageous). ${ }^{57}$ Research has consistently found that while healthy participants show a behavioral switch from the disadvantageous options to the low-risk advantageous options, patients with selective VMPFC lesions failed to show this switch, persisting in choosing the high-risk disadvantageous options, ${ }^{57,58}$ even with conceptual knowledge about the reinforcement contingencies of the task. ${ }^{59}$ Similarly, pathological gamblers who exhibit blunted VMPFC activities ${ }^{60,61}$ also show preference for the disadvantageous options while performing the $\mathrm{IGT}^{62}$ and engage in more risky behaviors on other gambling tasks. ${ }^{63}$ These findings collectively provide strong evidence that the VMPFC is a critical neural substrate for adaptive decision making based on the learning of reinforcement schedules associated with different response options. It was suggested that patients with ventral prefrontal lesions failed to generate corresponding "somatic marker" signals to the high-risk disadvantageous options that would have otherwise biased their choices away from those options toward the low-risk advantageous options. ${ }^{57}$ Thus, the ventromedial prefrontal region, through its connections with regions such as the hypothalamus and amygdala which are involved in biological regulations and emotions, ${ }^{64}$ function to establish the link between external stimuli and their corresponding emotive values and internal sensory signals based on reinforcement contingency information, thereby guiding selections among response alternatives. Consistent with this proposal, researchers have observed VMPFC activities during outcome evaluation in both a probabilistic gambling task ${ }^{53}$ and a financial, risky decision-making task. ${ }^{54}$

Evidence has also suggested important functional roles in risky decision making for the OFC/VLPFC. ${ }^{65}$ Patients with selective OFC lesions frequently report emotional impairments and deficits in forming flexible stimulus-reinforcement contingencies in accordance with changing environment, 
despite preserved working-memory functioning. ${ }^{66}$ Previous brain-imaging studies have also generated findings consistent with those of the lesion studies. One such study employed a probabilistic gambling task in which participants chose between high-risk options associated with smaller probability of winning and larger magnitudes of gains and losses (denoted by the smaller number of blue boxes at the top right and the larger value in blue at the bottom right, respectively, in Figure 1A), or low-risk options associated with larger win probability and smaller magnitudes of gains and losses (denoted by the larger number of red boxes at the top left and the smaller value in red at the bottom left, respectively, in Figure 1A).${ }^{54}$ The researchers observed OFC activations during decision making, and left OFC activities correlated positively with the level of conflict in making choices (Figure 1B). Other studies have found OFC activations during outcome anticipation that correlated with the level of risk on a cued probabilistic card-guessing game, ${ }^{67}$ as well as when choosing between options differing in terms of level of risk and reinforcement contingencies, ${ }^{68}$ consistent with the proposed functional role of this region in forming flexible stimulus-response-reinforcement associations in accordance with the changing environment, and in using this information to control behaviors. ${ }^{36,66}$

The DLPFC is involved in a range of cognitive executive functions such as working memory ${ }^{69,70}$ and attention, ${ }^{71}$ as
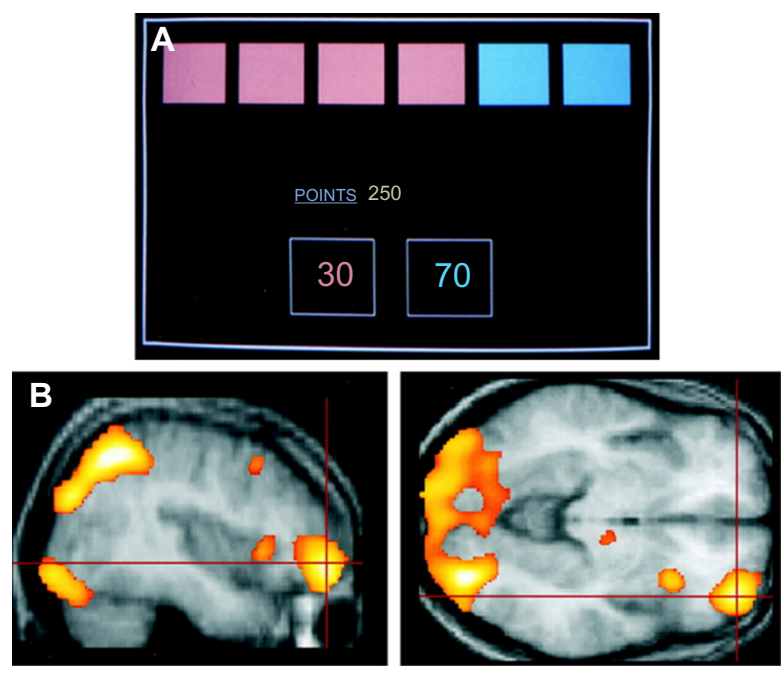

Figure I The Cambridge Gambling Task (CGT) and associated orbitofrontal activations.

Notes: (A) A typical display of the CGT. Participants guessed whether the token was hidden in the red or blue box, the probabilities of which were displayed as the number of red or blue boxes on the screen, respectively (ie, four [red] : two [blue] in the Figure). Lower probabilities of winning were always accompanied by larger magnitudes of gain or loss. (B) The gambling task relative to a visuomotor control activated right lateral orbitofrontal cortex (peak activation 40, 64, -8).

Adapted with permission of the Society for Neuroscience, from Choosing between small, likely rewards and large, unlikely rewards activates inferior and orbital prefrontal cortex. Rogers RD, Owen AM, Middleton HC, et al. 1999;20(19):9029_ 9038; permission conveyed through Copyright Clearance Center, Inc. ${ }^{54}$ revealed by patients with DLPFC lesions. ${ }^{66,72}$ Brain-imaging studies have found activations in the DLPFC while subjects chose between options differing in terms of the level of risk and reinforcement contingency, ${ }^{68}$ prior to risky compared with safe responses on the risky-gains task, ${ }^{73}$ and at high risk levels on the BART. ${ }^{74}$ The role of DLPFC in risky decision making might be to provide sufficient attentional and working-memory resources for effective integration and utilization of reinforcement contingency information in guiding action selection, ${ }^{57}$ with additional evidence suggesting the direct reactivity of DLPFC to external reward contingencies and the involvement of this region in initiating reward-based actions. ${ }^{75}$

The insular cortex has reciprocal connections with the anterior cingulate cortex (ACC) and $\mathrm{OFC},{ }^{64}$ as well as with limbic regions, ${ }^{76}$ and may link value information on external and internal stimuli to interoceptive bodily states. ${ }^{77}$ Consistent with this, anticipatory processes either prior to or following risky decision making that are likely to cause high levels of physiological and emotional arousal activate the insula. ${ }^{64,68,74,78}$ In addition, while ventral striatal (nucleus accumbens) activation predicted behavioral switching from safe to risky options, insular activation predicted switching from risky to safe options on a financial investment task. ${ }^{55}$ Thus, an important role of the insula in risky decision making may be in generating anticipatory aversive somatic marker signals to stimuli and responses previously associated with aversive outcomes, thus biasing individuals' action selection away from options that could potentially lead to heavy losses. ${ }^{73,79}$ As high-risk options are typically associated with larger losses,${ }^{8}$ insular activations prior to risky choices could function to steer participants' future responses away from those selections toward safer options, ${ }^{55,73}$ the propensity for which was related to personality-trait scores on harm avoidance and neuroticism. ${ }^{73}$

\section{The influence of aging on risky decision making}

Previous research has generated mixed findings on this topic. While a larger number of studies has suggested that risk seeking decreases and risk aversion increases with aging, ${ }^{80-82}$ other studies have found no such effect ${ }^{83,84}$ or even the opposite effect. ${ }^{85,86}$ Moreover, the relationship between risk-taking tendency and age may not be monotonous or linear. ${ }^{87,88}$

\section{Risk taking in laboratory experimental tasks}

Overall, studies that assessed the effect of aging on risk taking employing laboratory experimental paradigms have 
generated rather mixed results. ${ }^{81}$ In an early study, older adults were found to be more cautious than younger adults following success on a vocabulary task involving various levels of risk. ${ }^{80}$ Two more recent studies obtained results that were consistent with a negative relationship between aging and risk taking. One of those studies ${ }^{78}$ measured risk-taking behaviors using the "risky-gains task" ${ }^{73}$ which allows participants to make either safe responses that lead to small gains or risky responses that lead to either larger gains or larger losses. The findings showed that elderly participants made more safe responses and fewer risky responses than young participants. In the other study, ${ }^{81}$ young and elderly participants both performed a variant of the Cambridge Gambling Task, ${ }^{54}$ in which participants tried to guess whether a token was hidden in red or blue boxes, and could decide the stake to bet. The probabilities of winning and losing associated with the two choice options were presented to the participants on the screen (Figure 1A). The results again showed that older participants exhibited less "risk tolerance", defined as the average size of stakes placed, than younger participants, but younger participants showed greater adjustment of stakes to risk levels. Finally, a series of studies assessed younger and older participants" preferences on "risky" and "certain" choice options that involved either potential gains or potential losses, ${ }^{89-91}$ and consistently found that older participants were more risk averse than younger participants when deciding between a sure smaller gain and a risky larger gain. However, older participants expressed more risk seeking in the loss domain than younger participants. ${ }^{91}$ Further studies are needed to investigate the differential effects of aging on risky decision making in the gain and loss domains.

A few previous studies have generated findings suggesting greater preference for high-risk options on the IGT among some elderly participants compared with younger participants. ${ }^{85,92}$ Yet other studies have reported comparable performance on the IGT between young and elderly participants, ${ }^{93,94}$ with some indication that young participants showed greater extents of learning than older participants. ${ }^{95}$ Additionally, it has been shown that elderly adults are under greater recency effects during learning, ${ }^{95}$ possibly due to their declined memory functions, ${ }^{96}$ whereas young adults showed little such effect. Similarly, a subsequent study found that IGT performance correlated positively with immediate memory in older adults only. ${ }^{97}$ These findings suggest that performance differences between young and elderly participants on the IGT might be at least partly accounted for by declines in cognitive functions, such as episodic and working memory, with aging, ${ }^{2,98}$ besides possible aging-related deficits in response selection based on reinforcement associative learning. ${ }^{81,99}$ As described earlier, optimal performance on the IGT requires the integration of value information over time. ${ }^{58}$ However, elderly individuals with reduced memory functions may instead rely on outcome information in the immediate history, which may lead to impaired performance. ${ }^{58} \mathrm{On}$ task paradigms that provided explicit information on reinforcement contingencies and/or demanded little learning of stimulus-response-outcome associations over time, ${ }^{81,83}$ elderly participants tended to exhibit comparable or less risk taking than younger participants.

\section{Risk taking in self-report questionnaire measures}

Previous research that examined aging effect on risk taking employing questionnaire measures has mostly revealed a negative relationship between risk seeking and aging, ${ }^{100}$ with a few anomalies. ${ }^{86,101}$ An early study administered the Choice Dilemmas Questionnaire to people of different ages and found that older adults of either sex indicated higher minimal success probabilities for selecting the more risky options to hypothetical life scenarios. ${ }^{102}$ Later studies confirmed the negative relationship between aging and risk seeking on the Choice Dilemmas Questionnaire. ${ }^{82,103}$ Further, one study administered survey questions concerning financial risk and found people over 60 years old were more risk aversive than younger people, but risk tolerance rose slightly after 70 years old. ${ }^{104}$ However, a subsequent study administered financial risk-taking questionnaires to a sample of university employees in the USA, and found older adults were more risk tolerant, or more willing to make risky financial decisions, than younger participants. ${ }^{86}$ It might be that university employees who, on average, have achieved higher educational levels and are equipped with greater intellectual abilities, tend to show little decrease in risk-taking tendencies with age. Another study that revealed no effect of aging on risk taking also employed the Choice Dilemmas Questionnaire. ${ }^{101}$ However, in that study, young and elderly participants had different educational levels and marital statuses. Collectively, findings from previous research suggest an overall negative effect of aging on risk taking, although the precise relationship might depend on factors such as educational level. ${ }^{86,101}$

\section{Risk taking in real-life financial decisions}

Previous research examining the effect of aging on real-life financial decision making has generated consistent findings suggesting that financial risk aversion increases with aging. ${ }^{105-108}$ In the USA, as the average age rises, so do the 
risk premiums for assets, suggesting that risky financial investments become less popular as the population ages. ${ }^{105}$ There is also evidence that the relationship between age and financial risk aversion might not be monotonous. For example, at least two previous studies found that financial risk aversion declined with age until age 65, after which risk aversion increased. ${ }^{87,88}$ One possible reason for higher financial risk aversion among elderly people is that these individuals have less time, energy, and other personal resources to recover from the potential losses incurred from financial risk taking. ${ }^{7}$ Alternatively, it might be that, compared with young people, elderly individuals are more likely to have accumulated considerable assets in earlier parts of their lives which they are reluctant to lose through risk taking.

\section{Risky driving behaviors}

Previous studies have generally suggested that older age is associated with less risk taking in driving. ${ }^{109}$ For example, previous studies have consistently found that younger drivers commit more driving violations or deliberate risky driving behaviors than elderly drivers. ${ }^{110,111}$

\section{Risk taking in medical decision making}

Limited evidence indicates that risk aversion while deciding upon medical treatments increases with aging. When asked to make decisions on whether to undergo surgical procedures for recovering from deteriorating eyesight with the danger of becoming blind completely, older adults tended not to choose the more risky surgery option compared with younger adults, regardless of the surgery's probability of success. ${ }^{112}$ Moreover, elderly adults showed greater tendencies than younger adults to avoid or delay making medical decisions, ${ }^{113}$ which, in practice, is frequently equivalent to deciding against the more risky options such as undergoing screening or surgery. ${ }^{114}$

\section{Summary}

Previous studies that assessed the effect of aging on risky decision making using self-report questionnaire measures, real-life financial and medical decision-making measures, and driving behavior measures have generally indicated a negative relationship between aging and risk taking, although the relationship might not be unitary across the age spectrum. ${ }^{88,104}$ Studies employing laboratory experimental tasks have generated mixed findings regarding the effect of aging on risk taking, which might be due to several factors. First, some tasks, such as the IGT, require participants to learn sophisticated reinforcement contingencies over a prolonged course of performance, which might be challenging for some elderly adults with declining cognitive functions. ${ }^{92}$ Second, it might be that some laboratory tasks fail to create realistic risky scenarios that would elicit sufficient motivation and emotional arousal in participants. ${ }^{15}$ Third, in studies employing bet preference measures, ${ }^{91}$ each of several bet parameters, including risk (outcome variance), win/loss probability, win/loss magnitude, and expected value, may affect participants' decision outcomes. Also, subjective risk may differ from objective risk and depend on additional factors such as largest possible loss. ${ }^{115}$ Finally, there might exist substantial heterogeneity among the elderly population regarding cognitive abilities, emotional valuation, and risk attitudes. ${ }^{4,116}$ Thus, covariate studies examining the associations between performance on risky decision-making tasks and other cognitive/emotional functions might generate revealing findings. ${ }^{97}$

\section{Age, positivity, and risky decision making}

The $\mathrm{MMH},{ }^{14}$ which posits that mood-regulatory strategies aiming at maintaining positive affect states are generally associated with lesser risk-taking tendency, is useful in characterizing the effect of affect on risky decision making in elderly populations. There has been accumulating research evidence indicating that aging is associated with decrease in negative affects, ${ }^{15,16,117}$ moderate increase in positive affects, ${ }^{16,117,118}$ and better emotional regulation. ${ }^{15,16}$ One study investigated daily emotions among people aged 18-94 years old and found that negative emotional experience decreased in frequency until about age 60 then stabilized, even after controlling for factors such as personality, health, and demographic variables. ${ }^{15}$ In addition, among older people, highly positive emotional experiences tended to be more enduring, and highly negative emotional experiences were less stable. ${ }^{15}$ Lower levels of negative affect were also reported by elderly participants in the age range of 65-83 years old compared with by young participants, ${ }^{119}$ consistent with the suggestion that negative affect may decrease from early to late adulthood until the oldest years. ${ }^{120}$ Increase in the frequency of happy emotions, decrease in the frequency of negative emotions, and greater emotional control have each been found in elderly participants compared with in young participants. ${ }^{16}$

Besides the positive changes in affect with aging, previous studies have also revealed that elderly adults exhibit greater attention to, ${ }^{119,121}$ and have better episodic and working memory for, positive versus negative emotional stimuli ${ }^{122-124}$ than younger adults, who typically pay equal or more attention to negative stimuli. ${ }^{119,121}$ The differential cognitive processing 
of positive and negative emotional stimuli in young and elderly adults is also reflected in their neural responses to those stimuli. ${ }^{125}$ For example, one study documented insular activations during loss anticipation in young participants but not in elderly participants, suggesting a reduction in negative emotional processing in aged individuals. ${ }^{126}$

As described earlier, some researchers consider that positive mood would increase risk-taking tendency, as individuals with more positive mood may perceive the situation as more favorable and potential negative outcomes as less negative or less likely to occur. Such individuals may also act more readily to seek further happiness. ${ }^{13}$ In contrast, according to the socio-emotional selectivity theory, ${ }^{15}$ as individuals age, they switch life goals from knowledge acquisition to emotional satisfaction and enjoyments due to a change in time perspective. Thus, the positivity effect among elderly adults might be motivated by and contribute to emotional regulation through avoiding negative emotional states and intensifying positive emotional states when faced with negative aging-related declines in physical and mental aspects. ${ }^{15,16,125}$ This active regulation of emotions demands cognitive resources. When elderly participants' attentional resources were exhausted through stimulus distraction, they no longer showed the positivity effect they otherwise displayed in non-distracted conditions. ${ }^{119}$ Thus, elderly individuals may engage in less risk taking so as to reduce the potential for negative consequences and to preserve their positive mood, ${ }^{14}$ a mood-regulatory strategy analogous to their general inattentiveness to negative emotional stimuli. ${ }^{119,121}$ That being said, the possibility that the positivity effect potentiates rather than suppresses risk-seeking tendency cannot be completely ruled out, particularly among younger individuals who may be less concerned with mood regulation. ${ }^{15}$

Elderly adults' tendency to avoid negative emotional stimuli may have a specific influence on their medical decision making regarding risky treatment options. It has been suggested that older cancer patients may dismiss viable treatment options too quickly to avoid any potential negative consequences associated with risk taking ${ }^{127,128}$ but that this tendency could nevertheless be alleviated through conveying medical options in positive frames. ${ }^{129}$

\section{Risky decision making and the effect of aging on neurobiological systems and cognitive functioning}

Natural aging is associated with declines in neurotransmissions such as the dopaminergic systems (for a review, see Bäckman et al), ${ }^{3}$ as well as anatomical and functional atrophies in a wide range of neural networks, notably those involved in executive functions, such as the DLPFC, ${ }^{130}$ and regions involved in memory functions, such as the hippocampus. ${ }^{131}$ These neurobiological declines have marked impact on the attention, working memory, and episodic memory functions of elderly adults. ${ }^{2-4}$ These cognitive functional deteriorations, as well as impairments on reinforcement learning resulting from aging-related reductions of the dopaminergic systems, ${ }^{132}$ have joint influences on risky decision making among elderly adults. ${ }^{4,133}$

\section{Aging and the dopaminergic systems}

Previous research has indicated that the dopaminergic neural circuitries are significantly affected by aging. ${ }^{134}$ Researchers have observed aging-related reductions in dopamine cell bodies in the substantial nigra, ${ }^{135}$ where the nigrostriatal dopamine pathways originate. Other studies have found widespread reductions in postsynaptic dopamine D1 and D2 receptors, particularly in the frontal cortical and striatal regions. ${ }^{136-139}$ Researchers have also observed presynaptic aging-related reductions of the dopamine transporter protein in the striatum, ${ }^{140}$ which mediates aging-related cognitive deficits in episodic memory and executive functioning. ${ }^{141}$

Increase in dopaminergic transmission levels had an overall facilitatory effect on learning from rewards, whereas decrease in dopaminergic transmission enhanced avoidance learning from punishments. ${ }^{142}$ Consistent with this, older participants were slower in learning new stimulus-actionreward associations, ${ }^{143,144}$ but showed enhanced learning of negative stimuli. ${ }^{145}$ Further, young participants exhibited ventral striatal activations during reward anticipation, whereas elderly participants showed similar activations during reward delivery, suggesting deficits in reward learning with aging. ${ }^{146}$ Interestingly, a recent study investigated young and aged rats' preference over food reward options that varied in magnitude and probability, and found subgroups of rats showing deficits in forming valuations based on both magnitude and probability information, ${ }^{147}$ which might be due to aging-related declines in rats' dopaminergic systems.

\section{Aging and neuroanatomical and functional atrophy}

Natural brain aging is accompanied by atrophy and neuronal loss due to "apoptosis", or programmed cell death. ${ }^{4}$ Extensive evidence has indicated gray-matter shrinkage and white-matter alterations in relation to aging..$^{148-150}$ Generally, aging-related loss of brain tissues tends to be most severe in the frontal lobes. ${ }^{151,152}$ More specifically, the frontal region is 
comprised of distinct subdivisions, such as the DLPFC that is involved in executive functions and working memory, ${ }^{153}$ and ventromedial and VLPFC that are associated with emotional processing and regulations. ${ }^{154}$ Past research has suggested that aging may be particularly associated with functional declines in the dorsal and lateral parts of the prefrontal regions ${ }^{155-158}$ compared with ventral prefrontal cortex (PFC) regions. ${ }^{130,159}$ This concurs with findings from functional imaging studies suggesting that both elderly and young participants showed ventral PFC activations during a working-memory test, but young participants showed greater dorsolateral PFC activations than did elderly participants. ${ }^{160}$ Elderly participants also exhibited selective deficits in recruiting the DLPFC during learning new stimulus-response-reward associations. ${ }^{161}$ Research has also revealed aging-related volumetric reductions in the hippocampus. ${ }^{131,162}$

\section{Cognitive declines in aging}

The dopaminergic systems are involved in cognitive activities such as working memory, ${ }^{163,164}$ and there is evidence suggesting that aging-related reductions in dopamine receptors and the dopamine transporter protein in striatal regions contribute to elderly people's compromised executive, motor, and perceptual functioning, ${ }^{165}$ as well as declines in episodic memory and processing speed. ${ }^{140,166}$ According to neuro-computational models, dopamine systems represent the "gain" parameter in information processing, with aging-related declines in dopaminergic transmission leading to reductions in gain, which in turn lead to the under-responsiveness of neurons, greater variabilities in the system, and impaired cognitive capacity. ${ }^{132}$ In addition, elderly adults may experience declines in working memory and attention as a consequence of aging-related atrophy of DLPFC regions. ${ }^{94,158}$ For example, in a study employing a variant of the Wisconsin Card Sorting Task assessing attention shifting and working-memory functions, ${ }^{167}$ older participants performed worse than, and showed reduced DLPFC activations compared with, young participants. Consistent with this, selective aging-related impairments have been found on working-memory and executive control functions thought to depend on DLPFC activities. ${ }^{94}$

Further, research evidence indicates that elderly adults tend to exhibit more bilateral prefrontal activities compared with young adults while performing cognitive tasks, ${ }^{168-170}$ based on which the hemispheric asymmetry reduction in older adults model was proposed. ${ }^{171}$ It might be that the bilateral recruitment of prefrontal neural networks is a form of compensatory mechanism for aging-related declines in cognitive resources ${ }^{172}$ or processing speed. ${ }^{173}$ Alternatively, the bilateral
PFC activity might reflect a form of functional non-selectivity among the elderly. ${ }^{170}$

\section{Cognitive, emotional, and neurobiological theories: an integration}

In previous sections of this review, we discussed past research on emotional, cognitive, and neurobiological alterations with aging. We also reviewed behavioral findings on the relationship between aging and risk taking. In this section, we will attempt to combine evidence from different domains of research together and provide an integrative account of risky decision making among elderly individuals.

To our knowledge, there have been relatively few experiments combining behavioral risky decision-making paradigms with function imaging techniques in assessing the effects of aging on risk taking. One of these studies administered the risky-gains task ${ }^{73}$ to elderly and young male participants. ${ }^{78}$ In this task, researchers presented the participants with the numbers 20,40 , and 80 one at a time in an ascending sequence in each trial, and the participants could press a button upon seeing a number to win that number of points. However, responding to the number 20 always led to point gains (a safe response), whereas responding to 40 or 80 could lead to either point gains or losses (a risky response). Elderly males made more safe responses and fewer risky responses than did young males, suggesting an increase in risk aversion with aging. Functional imaging data showed that when neural signals associated with making risky responses were contrasted with those associated with making safe responses, elderly males showed greater activations in the right insula and right OFC compared with young males.

As discussed earlier, the OFC-insula circuitry is involved during risky decision making and may function to generate somatic marker signals, especially aversive ones, to stimuli and responses previously associated with punishing outcomes. ${ }^{54,55,57,58,73}$ Patients with OFC lesions typically exhibit decision-making deficits, such as in gambling tasks involving choice options associated with different sizes and probabilities of rewards and punishments. ${ }^{54}$ Thus, the elevated activities of the OFC-insula circuitry among elderly males, compared with young males, prior to making risky choices may reflect greater negative reactivities of elderly individuals to risky options that could potentially lead to penalizing outcomes, consistent with their behavioral differences in risk taking. This is also consistent with the emotion theories of aging, which propose that elderly individuals tend to be more risk aversive due to affect regulatory strategies aiming 
at maintaining positive mood state, ${ }^{14,15}$ which may depend on the OFC-insula circuitry ${ }^{126,154}$ that is relatively preserved among the elderly. ${ }^{158}$

Samanez-Larkin et al conducted two informative experiments on the neural basis of the relationship between aging and risky decision making, using the Behavioral Investment Allocation Strategy task. ${ }^{133,174}$ In this task, researchers presented participants with three response options in each trial, comprised of one safe option (bond) that always gave a small reward, and two risky options (stock) associated with different probabilities of large rewards and large punishments (Figure

A

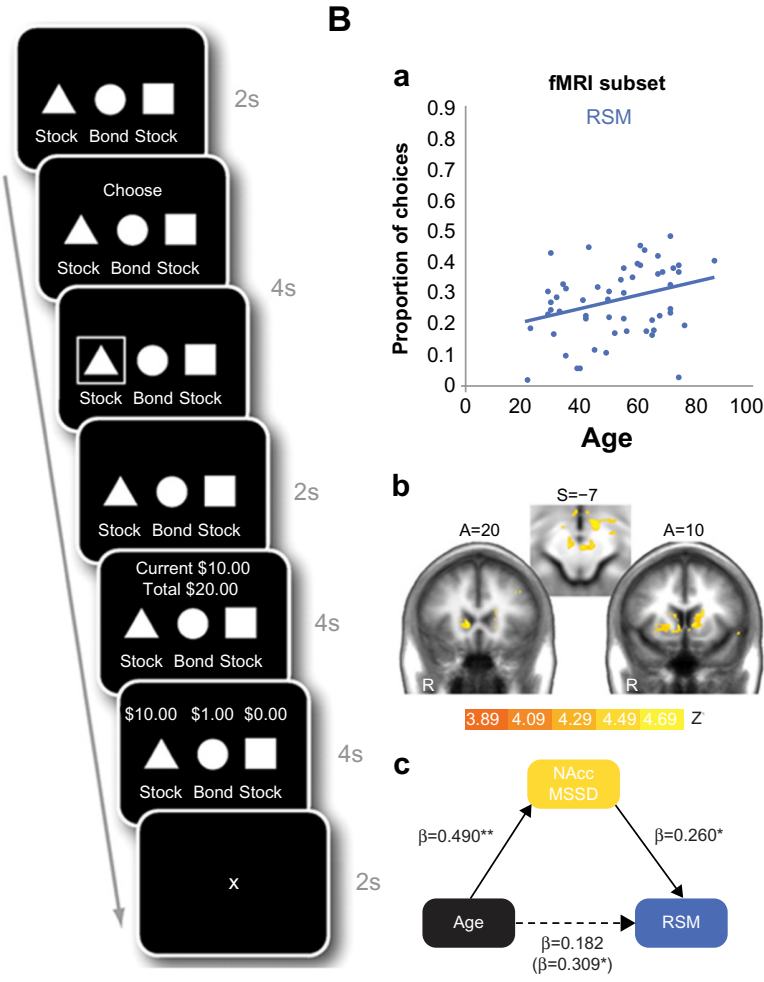

Figure 2 The Behavioral Investment Allocation Strategy (BIAS) task and associated age effect on behavioral and neural responses.

Notes: (A) During each trial, participants saw two stocks and a bond and were subsequently prompted to choose one from the three options. Following a waiting phase, the outcome of the current choice as well as those of the other two options were displayed as gain or loss of different amounts of US \$. The bond always gave a small reward and constituted a safe response. Both stocks gave a probabilistic reward and punishment, thus were more risky. However, one stock was "good" and led to higher probability of gain than loss, whereas the other was "bad" and led to higher chance of loss than gain. Stock allocation was performed at the start of each ten-trial block. Participants were not told about which stock was allocated as good or bad and had to work this out themselves through performing. (B) (a) Age showed a positive relationship with the frequency of risk-seeking mistakes, or selecting a stock when the rational choice should be the bond. (b) Age showed a positive relationship with temporal variability of neural signals in midbrain, ventral striatum (nucleus accumbens), and caudate regions. (c) The positive relationship between age and risk-seeking mistakes was mediated by temporal variability of nucleus accumbens signals. Adapted with permission of the Society for Neuroscience, from Variability in nucleus accumbens activity mediates age-related suboptimal financial risk taking. Samanez-Larkin GR, Kuhnen CM, Yoo DJ, Knutson B. 2010;30(4): 1426-1434; permission conveyed through Copyright Clearance Center, Inc. ${ }^{133}$

Abbreviations: $\mathrm{fMRI}$, functional magnetic resonance imaging; MSSD, mean squared successive difference; NAcc, nucleus accumbens; RSM, risk-seeking mistakes.
2A). One stock was "good" and gave a larger probability of reward than punishment, whereas the other stock was "bad" and gave a larger probability of punishment. The researchers did not tell the participants which stock was assigned as good or bad, and participants had to work it out themselves through performing the task. The researchers validated this task against financial achievement in the real world.

The behavioral results showed that, compared with young participants, elderly participants made more risk-seeking (Figure 2B) and confusion (choosing the bad stock instead of the good stock) mistakes in choice, even after controlling for factors such as education, numeracy skill, and digit span. Elderly participants' increased risk-taking mistakes were mediated by greater temporal variability of activities in the nucleus accumbens (Figure 2B) and caudate, consistent with previous research suggesting aging-related declines in striatal dopaminergic transmissions ${ }^{3}$ leading to reduced sensitivities of neuronal responses and greater signal variabilities. ${ }^{132}$ Thus, these results suggest that elderly adults have reduced capacity for utilizing information about the value of stimuli and responses across time to build dynamic models of stimulus-response-outcome contingencies. ${ }^{133}$

These findings were replicated and extended in a subsequent experiment, which showed that elderly participants' impaired performance in the Behavioral Investment Allocation Strategy task was due to a lack of coupling of their mesolimbic activities and the expected values of the response options. ${ }^{174}$ However, providing elderly participants with explicit information about the expected values improved those individuals' task performance to a level comparable to that of young participants. These findings add support to the suggestion that elderly individuals experience significant deficits in the dynamic learning of reinforcement contingencies over time, and concur with other behavioral findings showing that elderly adults may exhibit either riskseeking or risk-aversive tendencies on decision-making tasks, depending on the level of demand to learn a history of stimulus-response-outcome associations. ${ }^{78,80,85,92}$ In other words, elderly individuals may naïvely engage in seemingly risky behaviors not because they want to take more risks but because they do not realize that the behavioral option that they choose is more risky and/or disadvantageous. This hypothesis is also consistent with a recent meta-analysis showing that age differences in risk-seeking tendency are critically dependent on the learning requirement of the task, ${ }^{99}$ and with research evidence indicating a general association between risk-taking behaviors such as problem gambling and dysfunctional dopaminergic networks. ${ }^{175,45}$ 
However, it is not clear to what extent elderly participants' deficits in learning reinforcement contingencies over time result from specific impairments in reward-based associative learning ${ }^{145}$ or from aging-related declines in general cognitive functions such as memory and attention. ${ }^{2}$ Although the researchers controlled for some cognitive factors such as numeracy and working-memory capacity in the aforementioned study, ${ }^{133}$ it is still possible that aging-related differences in some other aspects of cognitive functioning may have contributed to the performance difference between the young and elderly. As recognized by some researchers, aging-related working-memory decline may affect economic decision making in ways beyond the aging effects on the processing of the probability or value of options. ${ }^{4}$ Similarly, it has been suggested that cognitive abilities such as working memory and processing speed influence the integration of information during reward or expected value estimations. ${ }^{5}$ Moreover, it has been found that aging-related differences in performance on the Cambridge Gambling Task and BART were largely mediated by individual differences in processing speed and memory. ${ }^{98}$ Further, there is evidence suggesting that attention deficits resulting from DLPFC dysfunctioning could lead to impaired performance on reinforcement learning tasks. ${ }^{72}$ Collectively, this evidence highlights the possibility that elderly individuals may settle on risky behavioral options without appreciating their risky nature because of a failure to integrate value-related information resulting from deficient cognitive resources and executive functioning.

Taken together, as people age, their negative emotional experiences decrease and positive affects increase, and they engage in more effective emotion regulation to maintain a positive affect state. ${ }^{15,16}$ As a result, they are less willing to engage in high-risk behaviors that could potentially lead to punishing consequences and negative emotional costs..$^{14,114}$ However, natural aging is also associated with neurobiological declines in both dopaminergic neurotransmission systems and in distinct functional regions such as the DLPFC, a consequence of which is that elderly individuals experience marked reductions in cognitive functions, as well as impaired ability in reward-based associative learning. ${ }^{2-4,145}$ Thus, elderly individuals may deviate from their characteristic risk-aversive tendencies and engage in risk-taking behaviors in situations in which task demands exceed their cognitive and/or reinforcement learning capacities, especially as positive emotional regulation takes up additional cognitive resources. ${ }^{119,123}$ These speculations demand extensive empirical testing, particularly with studies combining behavioral and functional imaging techniques in the investigation of the effects of aging-specific neural alterations on risky decision-making processes, ${ }^{133,174}$ as well as studies examining the cognitive correlates of aging-related differences in risky decision making. ${ }^{97}$ Some additional suggestions for directions of future research that could help validate and improve this theoretical model are presented in the next section.

\section{Implications and future directions}

The theoretical model we arrived at in the previous section, based on a review of behavioral, emotional, and neurobiological evidence in relation to both aging and risk taking, generates three research hypotheses that could be tested by future research. First, naturally aged individuals will generally show lesser risk-taking tendency in real-life scenarios, in response to questionnaires and on laboratory tasks that require little or no learning over time. Second, elderly participants' risktaking tendency when measured by tasks that place higher levels of demand of learning depend on participants' levels of cognitive executive functioning such as working memory and attention, and of reinforcement contingency learning ability, which are in turn dependent on the functioning level of their dorsolateral cortical networks and dopaminergic reinforcement circuitries. Third, elderly individuals who are better at emotion regulation, such as emotion control, ${ }^{16}$ are more risk aversive than those who are less proficient at regulating emotions.

In addition, future research in this field needs to employ appropriate task designs to best address the relationship between aging and risk taking, per se. As reviewed herein, aging-related declines in cognitive capacities may alter elderly participants' performance in risky decision-making tasks. ${ }^{2,5}$ Future research might do better to employ tasks that place a minimum demand on cognitive and learning capacities - through, for example, providing a constant visual display of relevant information or asking participants to make single-trial decisions that need not be based on a previous history of information. In this regard, the bet preference test, on which participants choose between alternative bets that differ in the level of risk associated, ${ }^{91}$ is a useful tool for assessing the aging effect on risk taking, provided that all the relevant bet parameters such as expected value, win/loss probability, win/loss magnitude, as well as risk are systematically controlled and manipulated. ${ }^{115}$ Moreover, the factor of motivation (eg, monetary versus nonmonetary tasks) may be important in influencing participants' decision outcomes. In tasks that provide real monetary reinforcements to participants, it is not guaranteed that young and elderly participants would perceive the same absolute amount of money as 
equally motivating. ${ }^{4}$ Future research may consider gauging the level of monetary reward in the task to the financial states of individual participants. Finally, aging-related difference, or lack of such difference, in real-life financial and medical risky decision making can be confounded by demographic, personality, and socioeconomic status differences between the young and the elderly. Such factors need to be controlled for with care in future research.

Further research is also needed to examine the substantial heterogeneity within the elderly population in risk taking. ${ }^{4,171}$ One major factor is sex, with extensive evidence indicating less risk-taking tendency in females than in males, ${ }^{177}$ and sex differences in neurobiological declines with aging. ${ }^{178}$ Thus, future studies may explicitly include sex as a modulatory factor when assessing the effect of aging on risky decision making.

Another important contributor of heterogeneity among the elderly is genetic factors, particularly genes that associate with the dopaminergic neurotransmission systems. ${ }^{3}$ Specifically, individuals carrying the val allele of the COMT gene show increased signal variability in the prefrontal regions compared with those carrying the met allele, ${ }^{179}$ consistent with the former individuals' worse performances on tasks assessing executive functions. ${ }^{116}$ Importantly, it was found that the effect of the different genotypes of COMT on cognitive functions was magnified with age, such that elderly participants carrying the val allele performed particularly poorly on cognitive tasks compared with elderly met allele carriers. ${ }^{116}$ Given recent evidence implicating the COMT gene in individual differences in risk-taking behaviors, ${ }^{30}$ future research is needed for detailed examinations of the role of the COMT, as well as other dopaminergic-related genes, in the relationship between aging and risky decision making.

Overall, past investigations have generated fairly consistent results suggesting an increase in financial risk aversion with aging. ${ }^{100,104,108}$ Thus, it might be more suitable for elderly adults to invest in safe bonds or stable enterprises, and to buy insurance, ${ }^{88}$ although there might also be considerable individual differences in financial risk preference among elderly individuals. ${ }^{86}$

Previous research has also suggested that elderly adults tend to seek less information and engage in less deliberation when deciding between medical alternatives, ${ }^{176}$ possibly as a result of reduced cognitive capacities and avoidance of stimuli associated with negative emotional costs. ${ }^{114}$ However, strategic measures such as conveying medical options in positive frames ${ }^{129}$ or patient decision aids providing detailed, specific, and highly personalized information pertaining to the treatment options and outcomes, can help elderly individuals considerably in making active and adaptive medical decisions. ${ }^{6}$

\section{Conclusion}

In this study, we characterized the relationship between natural aging and risky decision making through an integration of cognitive, emotional, and neurobiological theories on the effects of natural aging. Based on the evidence available, it is proposed that the positivity emotional bias in elderly adults steers them away from taking high risks and toward more cautious approaches as part of their positive emotional regulatory strategies. However, aging is associated with marked declines in cognitive functioning including, but not limited to, attention, processing speed, and working and episodic memories, as well as impaired reinforcement-based associative learning, arising from anatomical and functional declines in the dopaminergic transmission system and in distinct brain regions such as the DLPFC and hippocampus. As a result, elderly adults may deviate away from their usual conservative stance and toward more risk-taking tendencies, as observed in a subset of studies, if the demands of the risktaking task exceed their cognitive and learning capacities. Future empirical investigations are needed to determine the key factors that influence elderly individuals' decision making and behaviors in risky situations. Research in this field is likely to have important practical implications for the financial and medical decision making of elderly adults, as well as promoting designated help targeting the elderly population in making important life decisions.

\section{Acknowledgment}

This work is supported by the May Endowed Professorship of The University of Hong Kong and the Research Grant Council of Hong Kong Humanities and Social Sciences Prestigious Fellowship (Ref HKU703-HSS-13). The funders have had no role in the study design, data collection and analysis, decision to publish, or preparation of the manuscript.

\section{Disclosure}

The authors declare no conflicts of interest in this work.

\section{References}

1. Cairncross F. Economics: age, health and wealth. Nature. 2007;448: 875-876.

2. Grady CL. Functional brain imaging and age-related changes in cognition. Biol Psychol. 2000;54(1-3):259-281.

3. Bäckman L, Nyberg L, Lindenberger U, Li SC, Farde L. The correlative triad among aging, dopamine, and cognition: current status and future prospects. Neurosci Biobehav Rev. 2006;30(6):791-807. 
4. Brown S, Ridderinkhof KR. Aging and the neuroeconomics of decision making: A review. Cogn Affect Behav Neurosci. 2009;9(4):365-379.

5. Mohr PN, Li SC, Heekeren HR. Neuroeconomics and aging: neuromodulation of economic decision making in old age. Neurosci Biobehav Rev. 2010;34(5):678-688.

6. Stacey D, Bennett CL, Barry MJ, et al. Decision aids for people facing health treatment or screening decisions. Cochrane Database Syst Rev. 2011;(10):CD001431.

7. Yates JF, Patalano AL. Decision making and aging. In: Park D, Morrell R, Shifren K, editors. Processing of Medical Information in Aging Patients: Cognitive and Human Factors Perspectives. Mahwah, NJ: Lawrence Erlbaum Associates; 1999:31-54.

8. Slovic P. Perception of risk. Science. 1987;236(4799):280-285.

9. Mellers BA. Choice and the relative pleasure of consequences. Psychol Bull. 2000;126(6):910-924.

10. Savage LJ. The Foundations of Statistics. New York, NY: Wiley; 1954.

11. Kahneman D, Tversky A. Prospect theory: an analysis of decision under risk. Econometrica. 1979;47(2):263-291.

12. Bell DE. Risk, return and utility. Manage Sci. 1995;41:23-30.

13. Forgas JP. Mood and judgment: the affect infusion model (AIM). Psychol Bull. 1995;117(1):39-66.

14. Isen AM, Nygren TE, Ashby FG. Influence of positive affect on the subjective utility of gains and losses: it is just not worth the risk. J Pers Soc Psychol. 1988;55(5):710-717.

15. Carstensen LL, Pasupathi M, Mayr U, Nesselroade JR. Emotional experience in everyday life across the adult life span. J Pers Soc Psychol. 2000;79(4):644-655.

16. Gross JJ, Carstensen LL, Pasupathi M, Tsai J, Skorpen CG, Hsu AY. Emotion and aging: experience, expression, and control. Psychol Aging 1997;12(4):590-599.

17. Isen AM, Geva N. The influence of positive affect on acceptable level of risk: the person with a large canoe has a large worry. Organ Behav Hum Decis Process. 1987;39(2):145-154.

18. Isen AM, Pratkanis AR, Slovic P, Slovic L. The influence of positive affect on risk preference. Paper presented at the 92nd Annual Meeting of the American Psychological Association, August 24-28, 1984, Toronto, Ontario, Canada.

19. Chuang SC, Kung C. The effects of emotions in risk-taking. Journal of American Academy of Business Cambridge. 2005;6(2):113-118.

20. Raghunathan R, Pham MT. All negative moods are not equal: motivational influences of anxiety and sadness on decision making Organ Behav Hum Decis Process. 1999;79(1):56-77.

21. Webb TL, Sheeran P, Totterdell P, Miles E, Mansell W, Baker S. Using implementation intentions to overcome the effect of mood on risky behaviour. Br J Soc Psychol. 2012;51(2):330-345.

22. Yuen KS, Lee TM. Could mood state affect risk-taking decisions? $J$ Affect Disord. 2003;75(1):11-18

23. Schultz W. Dopamine neurons and their role in reward mechanisms Curr Opin Neurobiol. 1997;7(2):191-197.

24. Schultz W. Dopamine signals for reward value and risk: basic and recent data. Behav Brain Funct. 2010;6:24.

25. O’Doherty JP, Dayan P, Friston K, Critchley H, Dolan RJ. Temporal difference models and reward-related learning in the human brain Neuron. 2003;38(2):329-337.

26. O’Doherty JP, Buchanan TW, Seymour B, Dolan RJ. Predictive neural coding of reward preference involves dissociable responses in human ventral midbrain and ventral striatum. Neuron. 2006;49(1):157-166.

27. Bromberg-Martin ES, Matsumoto M, Hikosaka O. Distinct tonic and phasic anticipatory activity in lateral habenula and dopamine neurons. Neuron. 2010;67(1):144-155.

28. Fiorillo C, Tobler PN, Schultz W. Discrete coding of reward probability and uncertainty by dopamine neurons. Science. 2003;299(5614): 1898-1902.

29. Riba J, Krämer UM, Heldmann M, Richter S, Münte TF. Dopamine agonist increases risk taking but blunts reward-related brain activity. PLoS One. 2008;3(6):e2479.
30. Lancaster TM, Linden DE, Heerey EA. COMT val158met predicts reward responsiveness in humans. Genes Brain Behav. Epub August 17, 2012.

31. Lejuez CW, Read JP, Kahler CW, et al. Evaluation of a behavioral measure of risk taking: the Balloon Analogue Risk Task (BART). J Exp Psychol Appl. 2002;8(2):75-84.

32. Kuhnen CM, Chiao JY. Genetic determinants of financial risk taking. PLoS One. 2009;4(2):e4362.

33. Tanaka SC, Schweighofer N, Asahi S, et al. Serotonin differentially regulates short- and long-term prediction of rewards in the ventral and dorsal striatum. PLoS ONE. 2007;2:e1333.

34. Bechara A, Tranel D, Damasio H. Characterization of the decisionmaking deficit of patients with ventromedial prefrontal cortex lesions. Brain. 2000; 123:2189-202.

35. Knutson B, Taylor J, Kaufman M, Peterson R, Glover G. Distributed neural representation of expected value. J Neurosci. 2005;25:4806-4812.

36. Elliott R, Friston KJ, Dolan RJ. Dissociable neural responses in human reward systems. J Neurosci. 2000;20(16):6159-6165.

37. Schultz W, Preuschoff K, Camerer C, et al. Explicit neural signals reflecting reward uncertainty. Philos Trans $R$ Soc Lond B Biol Sci. 2008;363(1511):3801-3811.

38. Tobler PN, Christopoulos GI, O’Doherty JP, Dolan RJ, Schultz W. Neuronal distortions of reward probability without choice. J Neurosci. 2008;28(45):11703-11711.

39. Hsu M, Krajbich I, Zhao C, Camerer CF. Neural response to reward anticipation under risk is nonlinear in probabilities. $J$ Neurosci. 2009;29(7):2231-2237.

40. Breiter HC, Aharon I, Kahneman D, Dale A, Shizgal P. Functional imaging of neural responses to expectancy and experience of monetary gains and losses. Neuron. 2001;30(2):619-639.

41. Knutson B, Adams CM, Fong GW, Hommer D. Anticipation of increasing monetary reward selectively recruits nucleus accumbens. J Neurosci. 2001;21(16):RC159.

42. Seymour B, O’Doherty JP, Dayan P, et al. Temporal difference models describe higher-order learning in humans. Nature. 2004;429(6992): 664-667.

43. Balleine BW, Delgado MR, Hikosaka O. The role of the dorsal striatum in reward and decision-making. J Neurosci. 2007;27(31):8161-8165.

44. Gläscher J, Hampton AN, O’Doherty JP. Determining a role for ventromedial prefrontal cortex in encoding action-based value signals during rewardrelated decision making. Cereb Cortex. 2009;19(2):483-495.

45. Reuter J, Raedler T, Rose M, Hand I, Gläscher J, Büchel C. Pathological gambling is linked to reduced activation of the mesolimbic reward system. Nat Neurosci. 2005;8(2):147-148.

46. Walton ME, Croxson PL, Behrens TEJ, Kennerley SW, Rushworth MF. Adaptive decision making and value in the anterior cingulate cortex. Neuroimage. 2007;36 Suppl 2:T142-T154.

47. Leon MI, Shadlen MN. Effect of expected reward magnitude on the response of neurons in the dorsolateral prefrontal cortex of the macaque. Neuron. 1999;24(2):415-425.

48. Dreher JC, Kohn P, Berman KF. Neural coding of distinct statistical properties of reward information in humans. Cereb Cortex. 2006;16(4): $561-573$.

49. Galvan A, Hare TA, Davidson M, Spicer J, Glover G, Casey BJ. The role of ventral frontostriatal circuitry in reward-based learning in humans. J Neurosci. 2005;25(38):8650-8656.

50. Montague PR, Hyman SE, Cohen JD. Computational roles for dopamine in behavioural control. Nature. 2004;431(7010):760-767.

51. Hollerman JR, Tremblay L, Schultz W. Influence of reward expectation on behavior-related neuronal activity in primate striatum. JNeurophysiol. 1998;80(2):947-963.

52. Tremblay L, Hollerman JR, Schultz W. Modifications of reward expectation-related neuronal activity during learning in primate striatum. J Neurophysiol. 1998;80(2):964-977.

53. Rogers RD, Ramnani N, Mackay C, et al. Distinct portions of anterior cingulate cortex and medial prefrontal cortex are activated by reward processing in separable phases of decision-making cognition. Biol Psychiatry. 2004;55(6):594-602. 
54. Rogers RD, Owen AM, Middleton HC, et al. Choosing between small, likely rewards and large, unlikely rewards activates inferior and orbital prefrontal cortex. J Neurosci. 1999;20(19):9029-9038.

55. Kuhnen CM, Knutson B. The neural basis of financial risk taking. Neuron. 2005;47(5):763-770.

56. Everitt BJ, Morris KA, O'Brien A, Robbins TW. The basolateral amygdala-ventral striatal system and conditioned place preference: further evidence of limbic-striatal interactions underlying reward-related processes. Neuroscience. 1991;42(1):1-18.

57. Bechara A, Tranel D, Damasio H, Damasio AR. Failure to respond autonomically to anticipated future outcomes following damage to prefrontal cortex. Cereb Cortex. 1996;6(2):215-225.

58. Bechara A, Damasio H, Tranel D, Damasio AR. Deciding advantageously before knowing the advantageous strategy. Science. 1997;275(5304):1293-1295.

59. Maia TV, McClelland JL. A reexamination of the evidence for the somatic marker hypothesis: what participants really know in the Iowa gambling task. Proc Natl Acad Sci U S A. 2004;101(45):16075-16080.

60. Potenza MN, Leung HC, Blumberg HP, et al. An FMRI Stroop task study of ventromedial prefrontal cortical function in pathological gamblers. Am J Psychiatry. 2003;160(11):1990-1994.

61. Potenza MN, Steinberg MA, Skudlarski P, et al. Gambling urges in pathological gambling: a functional magnetic resonance imaging study. Arch Gen Psychiatry. 2003;60(8):828-836.

62. Cavedini P, Riboldi G, Keller R, D’Annucci A, Bellodi L. Frontal lobe dysfunction in pathological gambling patients. Biol Psychiatry. 2002;51(4):334-341.

63. Lawrence AJ, Luty J, Bogdan NA, Sahakian BJ, Clark L. Problem gamblers share deficits in impulsive decision-making with alcoholdependent individuals. Addiction. 2009;104(6):1006-1015.

64. Ongür D, Price JL. The organization of networks within the orbital and medial prefrontal cortex of rats, monkeys and humans. Cereb Cortex. 2000;10(3):206-219.

65. Ernst M, Paulus MP. Neurobiology of decision making: a selective review from a neurocognitive and clinical perspective. Biol Psychiatry. 2005;58(8):597-604.

66. Berlin HA, Rolls ET, Kischka U. Impulsivity, time perception, emotion and reinforcement sensitivity in patients with orbitofrontal cortex lesions. Brain. 2004;127(Pt 5):1108-1126.

67. Critchley HD, Mathias CJ, Dolan RJ. Neural activity in the human brain relating to uncertainty and arousal during anticipation. Neuron. 2001;29(2):537-545.

68. Ernst M, Bolla K, Mouratidis M, et al. Decision-making in a risk-taking task: a PET study. Neuropsychopharmacology. 2002;26(5):682-691.

69. Goldman-Rakic PS. The issue of memory in the study of prefrontal functions. In: Thierry AM, Glowinski J, Goldman-Rakic PS, Christen Y, editors. Motor and Cognitive Functions of the Prefrontal Cortex. Berlin: Springer; 1994:112-122.

70. Petrides M. Specialized systems for the processing of mnemonic information within the primate frontal cortex. Philos Trans R Soc Lond B Biol Sci. 1996;351(1346):1455-1461.

71. Dias R, Robbins TW, Roberts AC. Dissociation in prefrontal cortex of affective and attentional shifts. Nature. 1996;380(6569):69-72.

72. Hornak J, O’Doherty J, Bramham J, et al. Reward-related reversal learning after surgical excisions in orbito-frontal or dorsolateral prefrontal cortex in humans. J Cogn Neurosci. 2004;16(3):463-478.

73. Paulus MP, Rogalsky C, Simmons A, Feinstein JS, Stein MB. Increased activation in the right insula during risk-taking decision making is related to harm avoidance and neuroticism. Neuroimage. 2003;19(4): 1439-1448

74. Rao H, Korczykowski M, Pluta J, Hoang A, Detre JA. Neural correlates of voluntary and involuntary risk taking in the human brain: an fMRI Study of the Balloon Analog Risk Task (BART). Neuroimage. 2008;42(2):902-910.

75. Ballard IC, Murty VP, Carter RM, MacInnes JJ, Huettel SA, Adcock RA. Dorsolateral prefrontal cortex drives mesolimbic dopaminergic regions to initiate motivated behavior. J Neurosci. 2011;31(28):10340-10346.
76. Reynolds SM, Zahm DS. Specificity in the projections of prefrontal and insular cortex to ventral striatopallidum and the extended amygdala. J Neurosci. 2005;25(50):11757-11767.

77. Paulus MP, Stein, MB. An insular view of anxiety. Biol Psychiatry. 2006;60(4):383-387.

78. Lee TM, Leung AW, Fox PT, Gao JH, Chan CC. Age-related differences in neural activities during risk taking as revealed by functional MRI. Soc Cogn Affect Neurosci. 2008;3(1):7-15.

79. Mohr PN, Biele G, Heekeren HR. Neural processing of risk. J Neurosci. 2010;30(19):6613-6619.

80. Okun MA, Di Vesta FJ. Cautiousness in adulthood as a function of age and instructions. J Gerontol. 1976;31(5):571-576.

81. Deakin J, Aitkin M, Robbins T, Sahakian BJ. Risk taking during decision-making in normal volunteers changes with age. $J$ Int Neuropsychol Soc. 2004;10(4):590-598.

82. Vroom VH, Pahl B. Relationship between age and risk taking among managers. J Appl Psychol. 1971;55(5):399-405.

83. Dror IE, Katona M, Mungur K. Age differences in decision making: to take a risk or not? Gerontology. 1998;44(2):67-71.

84. Sanfey A, Hastie R. Judgment and decision making across the adult lifespan: a tutorial review of psychological research. In: Park D, Schwarz N, editors. Cognitive Aging: A Primer. Philadelphia, PA: Psychology Press; 2000:253-273.

85. Denburg N, BecharaA, TranelA, Hindes A, DamasioA. Neuropsychological evidence for why the ability to decide advantageously decreases with age. Society for Neuroscience Abstracts. 1999;21:24.

86. Grable JE. Financial risk tolerance and additional factors that affect risk taking in everyday money matters. J Bus Psychol. 2000;14(4): 625-630.

87. Riley WB Jr, Chow KV. Asset allocation and individual risk aversion. Financial Analysts Journal. 1992;48(6):32-37.

88. Halek M, Eisenhauer JG. Demography of risk aversion. Journal of Risk and Insurance. 2001;68(1):1-24

89. Lauriola M, Levin IP. Personality traits and risky decision-making in a controlled experimental task: an exploratory study. Pers Individ Dif. 2001;31(2):215-226.

90. Weller JA, Levin IP, Denburg NL. Trajectory of risky decision making for potential gains and losses from ages 5 to 85. J Behav Decis Mak. 2011;24(4):331-344.

91. Mather M, Mazar N, Gorlick MA, et al. Risk preferences and aging: the "Certainty Effect" in older adults' decision making. Psychol Aging. 2012;27(4):801-816.

92. Denburg NL, Tranel D, Bechara A, Damasio AR. Normal aging may compromise the ability to decide advantageously. Brain Cogn. 2001;47: $156-185$.

93. Kovalchik S, Camerer CF, Grether DM, Plott CR, Allman JM. Aging and decision making: a comparison between neurologically healthy elderly and young individuals. J Econ Behav Organ. 2005;58(1): 79-94.

94. MacPherson SE, Phillips LH, Della Sala S. Age, executive function, and social decision making: a dorsolateral prefrontal theory of cognitive aging. Psychol Aging. 2002;17(4):598-609.

95. Wood S, Busemeyer J, Koling A, Cox CR, Davis H. Older adults as adaptive decision makers: evidence from the Iowa Gambling Task. Psychol Aging. 2005;20(2):220-225.

96. Backman L, Small BJ, Wahlin A. Aging and memory: cognitive and biological perspectives. In: Birren JE, Schaie KW, editors. Handbook of the Psychology of Aging. 5th ed. San Diego, CA: Academic Press; 2001:349-377.

97. Fein G, McGillivray S, Finn P. Older adults make less advantageous decisions than younger adults: cognitive and psychological correlates. J Int Neuropsychol Soc. 2007;13(3):480-489.

98. Henninger DE, Madden DJ, Huettel SA. Processing speed and memory mediate age-related differences in decision making. Psychol Aging. 2010;25(2):262-270.

99. Mata R, Josef AK, Samanez-Larkin GR, Hertwig R. Age differences in risky choice: a meta-analysis. Ann N Y Acad Sci. 2011;1235:18-29. 
100. Dohmen T, Falk A, Huffman D, Sunde U, Schupp J, Wagner GG. Individual risk attitudes: new evidence from a large, representative, experimentally-validated survey. Discussion Papers of DIW Berlin 511. Berlin: DIW Berlin, German Institute for Economic Research; 2005.

101. Chou KL, Lee TM, Ho AH. Does mood state change risk taking tendency in older adults? Psychol Aging. 2007;22(2):310-318.

102. Wallach MA, Kogan N. Aspects of judgment and decision-making: interrelationships and changes with age. Behav Sci. 1961;6(1):23-36.

103. Okun MA, Stock WA, Ceurvorst RW. Risk taking through the adult life span. Exp Aging Res. 1980;6(5):463-473.

104. Barsky RB, Juster FT, Kimball MS, Shapiro MD. Preference parameters and behavioral heterogeneity: an experimental approach in the health and retirement study. Quarterly Journal of Economics 1997;112(2):537-579.

105. Bakshi GS, Chen Z. Baby boom, population aging, and capital markets. Journal of Business. 1994;67(2):165-202.

106. Brown DP. Age clienteles induced by liquidity constraints. International Economic Review. 1990;31(4):891-912.

107. Morin RA, Suarez F. Risk aversion revisited. Journal of Finance. 1983;38:1201-1216.

108. Palsson AM. Does the degree of relative risk aversion vary with household characteristics? J Econ Psychol. 1996;17(6):771-787.

109. Hakamies-Blomqvist L. Aging and fatal accidents in male and female drivers. J Gerontol. 1994;49(6):S286-S290.

110. Aberg L, Rimmö PA. Dimensions of aberrant driver behavior. Ergonomics. 1998;41(1):39-56.

111. Reason J, Manstead A, Stradling S, Baxter J, Campbell K. Errors and violations on the road: a real distinction? Ergonomics. 1990;33(10-11) 1315-1332.

112. Botwinick J. Cautiousness in advanced old age. J Gerontol. 1966;21: 347-353.

113. Finucane ML, Slovic P, Hibbard JH, Peters E, Mertz CK, MacGregor DG. Aging and decision-making competence: an analysis of comprehension and consistency skills in older versus younger adults considering health-plan options. J Behav Decis Mak. 2002;15(2):141-164.

114. Mather M. A review of decision-making processes: weighing the risks and benefits of aging. In: Carstensen LL, Hartel CR, editors. When I'm 64. Washington DC: National Academies Press; 2006:145-173.

115. Slovic P. Assessment of risk taking behavior. Psychol Bull. 1964;61(3): 220-233.

116. Nagel IE, Chicherio C, Li SC, et al. Human aging magnifies genetic effects on executive functioning and working memory. Front Hum Neurosci. 2008;2:1.

117. Löckenhoff CE, Carstensen LL. Socioemotional selectivity theory, aging, and health: the increasingly delicate balance between regulating emotions and making tough choices. J Pers. 2004;72(6): 1395-1424.

118. Mroczek D, Kolarz CM. The effect of age on positive and negative affect: a developmental perspective on happiness. J Pers Soc Psychol. 1998;75(5):1333-1349.

119. Knight M, Seymour TL, Gaunt JT, Baker C, Nesmith K, Mather M. Aging and goal-directed emotional attention: distraction reverses emotional biases. Emotion. 2007;7(4):705-714.

120. Mroczek DK. Age and emotion in adulthood. Curr Dir Psychol Sci. 2001;10(3):87-90.

121. Mather M, Carstensen LL. Aging and attentional biases for emotional faces. Psychol Sci. 2003;14(5):409-415.

122. Charles ST, Mather M, Carstensen LL. Focusing on the positive: age differences in memory for positive, negative, and neutral stimuli. J Exp Psychol. 2003;85:163-178.

123. Mather M, Knight M. Goal-directed memory: the role of cognitive control in older adults' emotional memory. Psychol Aging. 2005;20(4): 554-570.

124. Mikels JA, Larkin GR, Reuter-Lorenz PA, Carstensen LL. Divergent trajectories in the aging mind: changes in working memory for affective versus visual information with age. Psychol Aging. 2005;20(4): $542-553$.
125. Leclerc CM, Kensinger EA. Age-related differences in medial prefrontal activation in response to emotional images. Cogn Affect Behav Neurosci. 2008;8(2):153-164.

126. Samanez-Larkin GR, Gibbs SE, Khanna K, Nielsen L, Carstensen LL, Knutson B. Anticipation of monetary gain but not loss in healthy older adults. Nat Neurosci. 2007;10(6):787-791.

127. Pierce PF. Deciding on breast cancer treatment: a description of decision behavior. Nurs Res. 1993;42(1):22-28.

128. Pierce PF. When the patient chooses: describing unaided decisions in health care. Hum Factors. 1996;38(2):278-287.

129. Malloy TR, Wigton RS, Meeske J, Tape TG. The influence of treatment descriptions on advance medical directive decisions. JAm Geriatr Soc. 1992;40(12):1255-1260.

130. Raz N. Aging of the brain and its impact on cognitive performance: integration of structural and functional findings. In: Craik FI, Salthouse TA, editors. Handbook of Aging and Cognition. Mahwah, NJ: Erlbaum; 2000:1-90.

131. Mueller EA, Moore MM, Kerr DC, et al. Brain volume preserved in healthy elderly through the eleventh decade. Neurology. 1998;51(6): 1555-1562.

132. Li SC, Lindenberger U, Sikström S. Aging cognition: from neuromodulation to representation. Trends Cogn Sci. 2001;5(11): 479-486.

133. Samanez-Larkin GR, Kuhnen CM, Yoo DJ, Knutson B. Variability in nucleus accumbens activity mediates age-related suboptimal financial risk taking. J Neurosci. 2010;30(4):1426-1434.

134. Kaasinen V, Rinne JO. Functional imaging studies of dopamine system and cognition in normal aging and Parkinson's disease. Neurosci Biobehav Rev. 2002;26(7):785-793.

135. Kraytsberg Y, Kudryavtseva E, McKee AC, Geula C, Kowall NW, Khrapko K. Mitochondrial DNA deletions are abundant and cause functional impairment in aged human substantia nigra neurons. Nat Genet. 2006;38(5):518-520.

136. Inoue M, Suhara T, Sudo Y, et al. Age-related reduction of extrastriatal dopamine D2 receptor measured by PET. Life Sci. 2001;69(9): 1079-1084.

137. Antonini A, Leenders KL. Dopamine D2 receptors in normal human brain: effect of age measured by positron emission tomography (PET) and [11C]-raclopride. Ann NY Acad Sci. 1993;695: 81-85.

138. Wang Y, Chan GL, Holden JE, et al. Age-dependent decline of dopamine D1 receptors in human brain: a PET study. Synapse. 1998;30(1): 56-61.

139. Suhara T, Fukuda H, Inoue O, et al. Age-related changes in human D1 dopamine receptors measured by positron emission tomography. Psychopharmacology (Berl). 1991;103(1):41-45.

140. Mozley LH, Gur RC, Mozley PD, Gur RE. Striatal dopamine transporters and cognitive functioning in healthy men and women. Am J Psychiatry. 2001;158(9):1492-1499.

141. Erixon-Lindroth N, Farde L, Wahlin TB, Sovago J, Halldin C, Bäckman $\mathrm{L}$. The role of the striatal dopamine transporter in cognitive aging. Psychiatry Res. 2005;138(1):1-12.

142. Frank MJ, O’Reilly RC. A mechanistic account of striatal dopamine function in human cognition: psychopharmacological studies with cabergoline and haloperidol. Behav Neurosci. 2006;120(3): 497-517.

143. Mell T, Heekeren HR, Marschner A, Wartenburger I, Villringer A, Reischies FM. Effect of aging on stimulus-reward association learning. Neuropsychologia. 2005;43(4):554-563.

144. Fera F, Weickert TW, Goldberg TE, et al. Neural mechanisms underlying probabilistic category learning in normal aging. JNeurosci. 2005;25(49):11340-11348.

145. Frank MJ, Kong L. Learning to avoid in older age. Psychol Aging 2008;23(2):392-398.

146. Schott BH, Niehaus L, Wittmann BC, et al. Ageing and early-stage Parkinson's disease affect separable neural mechanisms of mesolimbic reward processing. Brain. 2007;130(Pt 9):2412-2424. 
147. Gilbert RJ, Mitchell MR, Simon NW, Bañuelos C, Setlow B, Bizon JL. Risk, reward, and decision-making in a rodent model of cognitive aging. Front Neurosci. 2012;5:144.

148. Good CD, Johnsrude IS, Ashburner J, Henson RN, Friston KJ, Frackowiak RS. A voxel-based morphometric study of ageing in 465 normal adult human brains. NeuroImage. 2001;14(1 Pt 1): 21-36.

149. Pfefferbaum A, Sullivan EV, Hedehus M, Lim KO, Adalsteinsson E, Moseley M. Age-related decline in brain white matter anisotropy measured with spatially corrected echo-planar diffusion tensor imaging. Magn Reson Med. 2000;44(2):259-268.

150. Ge Y, Grossman RI, Babb JS, Rabin ML, Mannon LJ, Kolson DL. Age-related total gray matter and white matter changes in normal adult brain. Part I: volumetric MR imaging analysis. Am J Neuroradiol. 2002;23(8):1327-1333.

151. Coffey CE, Wilkinson WE, Parashos IA, et al. Quantitative cerebral anatomy of the aging human brain: a cross-sectional study using magnetic resonance imaging. Neurology. 1992;42(3 Pt 1): 527-536.

152. Raz N, Gunning FM, Head D, et al. Selective aging of the human cerebral cortex observed in vivo: differential vulnerability of the prefrontal gray matter. Cereb Cortex. 1997;7(3):268-282.

153. Petrides M, Milner B. Deficits on subject-ordered tasks after frontaland temporal-lobe lesions in man. Neuropsychologia. 1982;20(3): 249-262.

154. Rolls ET. The orbitofrontal cortex. Philos Trans $R$ Soc Lond B Biol Sci. 1996;351(1346):1433-1444.

155. Hedden T, Gabrieli JD. Insights into the ageing mind: a view from cognitive neuroscience. Nat Rev Neurosci. 2004;5(2):87-97.

156. Mittenberg W, Seidenburg M, O'Leary DS, DiGiulio DV. Changes in cerebral functioning associated with normal aging. J Clin Exp Neuropsychol. 1989;11(6):918-932.

157. Daigneault S, Braun CM. Working memory and the Self-Ordered Pointing Task: further evidence of early prefrontal decline in normal aging. J Clin Exp Neuropsychol. 1993;15(6):881-895.

158. West RL. An application of prefrontal cortex function theory to cognitive aging. Psychol Bull. 1996;120(2):272-292.

159. Terry RD, DeTeresa R, Hansen LA. Neocortical cell counts in normal human adult aging. Ann Neurol. 1987;21(6):530-539.

160. Rypma B, Prabhakaran V, Desmond JE, Gabrieli JD. Age differences in prefrontal cortical activity in working memory. Psychol Aging. 2001;16(3):371-384.

161. Mell T, Wartenburger I, Marschner A, Villringer A, Reischies FM, Heekeren HR. Altered function of ventral striatum during reward-based decision making in old age. Front Hum Neurosci. 2009;3:34.

162. Jack CR Jr, Petersen RC, XuY, et al. Rate of medial temporal lobe atrophy in typical aging and Alzheimer's disease. Neurology. 1998;51(4): 993-999.

163. Fried I, Wilson CL, Morrow JW, et al. Increased dopamine release in the human amygdala during performance of cognitive tasks. Nat Neurosci. 2001;4(2):201-206.
164. Diamond A, Briand L, Fossella J, Gehlbach L. Genetic and neurochemical modulation of prefrontal cognitive functions in children. Am J Psychiatry. 2004;161(1):125-132.

165. Volkow ND, Gur RC, Wang GJ, et al. Association between decline in brain dopamine activity with age and cognitive and motor impairment in healthy individuals. Am J Psychiatry. 1998;155(3):344-349.

166. Bäckman L, Ginovart N, Dixon RA, et al. Age-related cognitive deficits mediated by changes in the striatal dopamine system. Am JPsychiatry. 2000;157(4):635-637.

167. Nagahama Y, Fukuyama H, Yamauchi H, et al. Age-related changes in cerebral blood flow activation during a Card Sorting Test. Exp Brain Res. 1997;114(3):571-577.

168. Grady CL, Bernstein LJ, Beig S, Siegenthaler AL. The effects of encoding task on age-related differences in the functional neuroanatomy of face memory. Psychol Aging. 2002;17(1):7-23.

169. Cabeza R, Grady CL, Nyberg L, et al. Age-related differences in neural activity during memory encoding and retrieval: a positron emission tomography study. J Neurosci. 1997;17(1):391-400.

170. Madden DJ, Turkington TG, Provenzale JM, et al. Adult age differences in the functional neuroanatomy of verbal recognition memory. Hum Brain Mapp. 1999;7(2):115-135.

171. Cabeza R. Hemispheric asymmetry reduction in older adults: the HAROLD model. Psychol Aging. 2002;17(1):85-100.

172. Kahneman D. Attention and Effort. Englewood Cliffs, NJ: Prentice Hall; 1973.

173. Salthouse TA. The processing-speed theory of adult age differences in cognition. Psychol Rev. 1996;103(3):403-428.

174. Samanez-Larkin GR, Wagner AD, Knutson B. Expected value information improves financial risk taking across the adult life span. Soc Cogn Affect Neurosci. 2011;6(2):207-217.

175. Voon V, Thomsen T, Miyasaki JM, et al. Factors associated with dopaminergic drug-related pathological gambling in Parkinson disease. Arch Neurol. 2007;64(2):212-216.

176. Meyer BJ, Russo C, Talbot A. Discourse comprehension and problem solving: decisions about the treatment of breast cancer by women across the life span. Psychol Aging. 1995;10(1):84-103.

177. Powell M, Ansic D. Gender differences in risk behaviour in financial decision-making: an experimental analysis. J Econ Psychol. 1997;18(6):605-628.

178. Murphy DG, DeCarli C, McIntosh AR, et al. Sex differences in human brain morphometry and metabolism: an in vivo quantitative magnetic resonance imaging and positron emission tomography study on the effect of aging. Arch Gen Psychiatry. 1996;53(7):585-594.

179. Winterer G, Musso F, Vucurevic G, et al. COMT genotype predicts BOLD signal and noise characteristics in prefrontal circuits. Neuroimage. 2006;32(4):1722-1732.

180. Coombs CH, Pruitt DG. Components of risk in decision making: probability and variance preferences. J Exp Psychol. 1960;60(5): 265-277.

181. Torrance EP, Ziller RC. Risk and Life Experience: Development of a Scale for Measuring Risk-Taking Tendencies. The Center; 1957.
Neuroscience and Neuroeconomics

\section{Publish your work in this journal}

Neuroscience and Neuroeconomics is an international, peer-reviewed, open access journal focusing on the identification of brain structures and measurement of neural activity related to behavior, behavioral predictions, and decision making in health and disease. The manuscript management system is completely online and includes a very quick and

\section{Dovepress}

fair peer-review system. Visit http://www.dovepress.com/testimonials. php to read real quotes from published authors. 